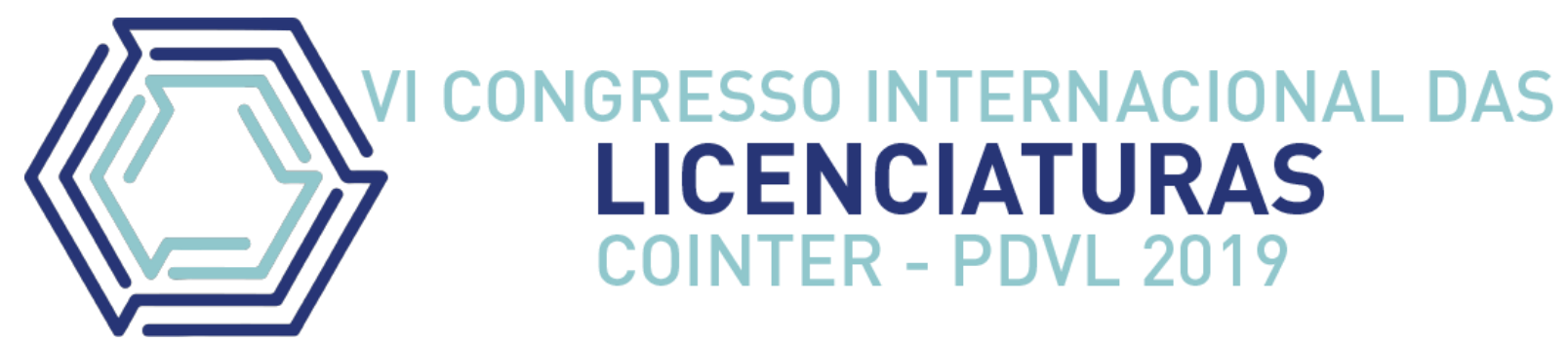

\title{
A IMPORTÂNCIA DA LÍNGUA ESPANHOLA NO TURISMO DO RIO GRANDE DO NORTE
}

\section{LA IMPORTANCIA DE LA LENGUA ESPAÑOLA EN EL TURISMO DE RIO GRANDE DO NORTE}

\section{THE IMPORTANCE OF THE SPANISH LANGUAGE IN THE TOURISM OF RIO GRANDE DO NORTE}

\author{
Apresentação: Comunicação Oral
}

Lucas Alves de Oliveira $^{1}$; Maria Trinida Pacherrez Velasco ${ }^{2}$

\section{DOI: https://doi.org/10.31692/2358-9728.VICOINTERPDVL.2019.0137}

\section{Resumo}

Este trabalho tem por objetivo analisar e refletir acercada importância da língua espanhola no turismo do Rio Grande do Norte (RN), baseando-se em dados coletados que revelam a realidade dos envolvidos nesse segmento e que levam à clara conclusão de que se faz necessário o conhecimento da língua espanhola para uma melhor qualidade nos serviços turísticos do estado do Rio Grande do Norte. Os dados analisados mostram que é maior o número de pessoas que trabalham no turismo sem saber falar espanhol, embora fique demonstrados com dados oficiais que a maioria dos turistas que visitam o estado do RN vêm de países hispano falantes. Concluímos que se faz necessário implementar políticas educacionais no $\mathrm{RN}$ que atendam também às necessidades econômicas do estado, de forma haja uma complementação entre as políticas públicas, sendo elas pensadas de maneira conjunta e que visem sempre o desenvolvimento e melhoria de vida do cidadão potiguar.

Palavras-Chave:Língua Espanhola, Turismo, Economia, Educação, Rio Grande do Norte.

\section{Resumen}

Este artículo científico tiene como objetivo analizar y reflexionar sobre la importancia del idioma español en el turismo en el estado de Rio Grande do Norte - RN, en Brasil, y se basó en datos recopilados que revelan la realidad de los involucrados en este segmento y conducen a la clara conclusión de que es necesario el conocimiento del idioma español para una mejor calidad de los servicios turísticos en Rio Grande do Norte. Los datos analizados muestran que hay muchas personas que trabajan en turismo sin hablar español, aunque se muestra con datos oficiales que la mayoría de los turistas que visitan el estado de RN provienen de países de habla hispana. Concluimos que es necesario implementar políticas educativas en RN que también satisfagan las necesidades económicas del estado, de modo que resulte en una

\footnotetext{
${ }^{1}$ Aluno do curso de Licenciatura em Espanhol - IFRN/CNAT, lucas16alvesru@ hotmail.com

${ }^{2}$ Doutora, professora do IFRN/CNAT, maria.velasco@ifrn.edu.br
} 
complementación entre políticas públicas, pensadas juntas y siempre con el objetivo de desarrollar y mejorar la vida del ciudadano Potiguar.

Palabras Clave:Lengua Española, Turismo, Economía, Educación, Rio Grande do Norte.

\begin{abstract}
This paper aims to analyze and reflect on the importance of the Spanish language in tourism in the state of Rio Grande do Norte - RN, in Brazil, and it was based on collected data which reveal the reality of those involved in this segment and lead to the clear conclusion that it is necessary the knowledge of the Spanish language for better quality tourism services in Rio Grande do Norte. The data analyzed show that there are more people who work in tourism without speaking Spanish, although it is shown with official data that most tourists visiting the state of RN come from Spanish speaking countries. We conclude that it is necessary to implement educational policies in RN that also meet the economic needs of the state, so that it results in a complementation between public policies, being thought together and always aiming at the development and improvement of life of the Potiguar citizen.
\end{abstract}

Keywords: Spanish language, Tourism, Economy, Education, Rio Grande do Norte.

\title{
Introdução
}

Por acreditar que o turismo de uma cidade, região ou país dinamiza a economia, o mercado de trabalho, o ânimo de uma população e impulsionao seu crescimento, compreendemos que há uma forte ligação deste setor econômico com o conhecimento da língua espanhola, visto que no Brasil elaé a língua falada pela grande maioria dos estrangeiros, sobretudo por aqueles que visitam o estado do Rio Grande do Norte (RN). Dito isso, enxergamos a importância da sua presença nos programas de ensino na rede básica educacional do Rio Grande do Norte.

Segundo dados de estudo realizado pela Federação de Comércio do Rio Grande do Norte (Fecomercio/RN), o número de turistas estrangeiros oriundos de países hispânicos em 2018 representou 96\% dos visitantes internacionais no Rio Grande do Norte durante a alta temporada. A partir da grande presença hispânica no Rio Grande do Norte, como é mostrado no estudo, inferimos que, em sua grande maioria, o turista estrangeiro que visita o estado é falante de espanhol.

No entanto, percebemos que no âmbito da educação, por meioda revogação da Lei 11.161, conhecida como "Lei do espanhol", e o consequente fim da obrigatoriedade da oferta do seu ensino nas escolas brasileiras, houve uma considerável redução do número de professores de Espanhol como Língua Estrangeira (E/LE)em atuação na rede estadual básica 
de ensino do RN.

Como consequênciaóbvia ao antes dito, o número de alunos de escolas públicas com acesso ao ensino gratuito de espanhol também acaba sendo reduzido, retirando-lhes a oportunidade de finalizarem a escola melhor capacitados segundo as necessidades exigidas pelo mercado de trabalho do Rio Grande do Norte. É uma perda de mão dupla, já que o estado em si acaba perdendo em número pessoas capacitadas para atenderem as suas demandas econômicas.

Deixamos claro que nós não defendemos o ensino de E/LE unicamente com fins econômicos, já que o seu caráter cultural e social é por si só altamente positivo para todos aqueles que têm a oportunidade em aprendê-la.

Levando em consideração a revogação da Lei 11.161/05 e o seu impacto e relevância no RN, acreditamos que este trabalho serve de suporte para a revisão e até mesmo formulação de políticas públicas voltadas tanto para osetor educacional, por meio do seu ensino nas escolas potiguares, quanto econômico, devido à sua importância no setor turístico local.

Acreditamos haver uma relação entre políticas voltadas para o turismo e para o ensino, já que a educação também pode ser percebida como capacitação de pessoal para o trabalho, gerando uma maior qualificação dos profissionais que estarão trabalhando no turismo potiguar.

Além disso, nos respaldamos no artigo 205 da Constituição, no qual é afirmado que a educação deve visionar o "pleno desenvolvimento da pessoa, seu preparo para o exercício da cidadania e sua qualificação para o trabalho" (BRASIL, 1988).

Inicialmente, optamos por abordar o quão presente é a língua espanhola atualmente no mundo e no Brasil. Em seguida, como forma de adentrar em ponto importante do trabalho, nós falamos sobre as características gerais do turismo no Rio Grande do Norte, e na sequência apresentamos dados que serão objeto de análise e reflexão sobre a presença da língua espanhola no turismo do Rio grande do Norte e a influencia deste conhecimento na hora de qualificar-se para o mercado de trabalho.

\section{Fundamentação Teórica}

Neste tópico defendemos o relevante significado que o conhecimento da língua espanhola tem para a sociedade potiguar como um todo, em diferentes âmbitos e com importante impacto na vida do cidadão e no desenvolvimento econômico do Estado. 


\section{O espanhol no mundo}

Segundo o Informe $2018^{3}$ do Instituto Cervantes "El español: una lengua viva”, elaborado em colaboração com a Agencia Estatal Boletín Oficial del Estado (AEBOE), 7,6\% da população mundial fala espanhol, o que em números gira em torno de 577 milhões de pessoas, sendo que 480 milhões delas têm o espanhol como língua materna, tornando-a a $2^{\circ}$ maior em número de falantes nativos, atrás apenas do mandarim. São quase 22 milhões de pessoas que a estudam em 107 países, e atualmente é a $3^{\circ}$ língua mais utilizada na internet, sendo 8,1\% da comunicação onlineproduzida em espanhol (Cervantes, 2018).

Na tabela 1 nós temos o ranking mundial dos países que possuem a maior quantidade de estudantes de espanhol como língua estrangeira (E/LE). O Brasil ocupa a $2^{\circ}$ posição, realidade que demostra o interesse e/ou a afinidade do brasileiro em aprender essa língua.

Tabela 1: Ranking de países com maior número de estudantes de espanhol.

\begin{tabular}{|c|c|}
\hline \multicolumn{2}{|l|}{$\begin{array}{l}\text { Países com maior número de estudantes de espanhol como língua estrangeira } \\
(\mathrm{E} / \mathrm{LE})\end{array}$} \\
\hline Estados Unidos & 8.157 .368 \\
\hline Brasil & 6.120 .000 \\
\hline França & 2.589 .717 \\
\hline Itália & 687.152 \\
\hline Costa do Marfim & 566.178 \\
\hline Alemanha & 554.423 \\
\hline Reino Unido & 519.660 \\
\hline
\end{tabular}

Elaboração própria. Fonte Instituto Cervantes, 2018.

A riqueza cultural envolvendo a língua espanhola é indiscutível. Embora ela se mantenha em um $2^{\circ}$ plano no âmbito internacional, a produção técnica e científica em naçõeshispanas vem crescendo desde 1996, e a projeção é que a sua literatura, música e pintura alcancem os mais variados países do mundo.

Ainda segundo o Instituto Cervantes, a participação dos países hispanos no PIB mundial é de $6,9 \%$, porcentagem superior à dos países que possuem o francês como língua

\footnotetext{
${ }^{3}$ Disponível em: 〈https://cvc.cervantes.es/lengua/espanol_lengua_viva/pdf/espanol_lengua_viva_2018.pdf〉. Acesso em agosto de 2019.
} 
oficial, por exemplo. Ainda de acordocom o instituto, a língua comum entre países falantes de espanhol multiplica 4 vezes o comércio bilateral entre eles.

Em termos de influência mundial, a língua espanhola ocupa a $4^{\circ}$ posição, e tal medida é feita a partir de fatores como dispersão e extensão geográfica, peso econômico, utilização na transmissão de conhecimento e uso no âmbito diplomático (Cervantes, 2018).

\section{O espanhol no Brasil}

Em termos geográficos, o território brasileiro é cercado por países que possuem o espanhol como língua oficial. Na América do Sul há 9 naçõesfalantes de espanhol, sendo 7 dessas limítrofes com o Brasil. Tal fatortorna as relações desenvolvidas pelo Brasil junto a esses países um fator incontornável à diplomacia brasileira (SIMÕES, 2011).

Em meados dos anos 80, o relacionamento do Brasil com países sul-americanos cresceu de uma forma bastante acentuada em relação aos anos anteriores. Em 1985, a Declaração de Iguaçu foi assinada por Argentina e Brasil, abrindo espaço para uma integração econômica no Cone-Sul ${ }^{4}$. Alguns anos depois, em 1991, foi assinado o Tratado de Assunção, instrumento jurídico utilizado para a criação do Mercado Comum do Sul (MERCOSUL), formado por Argentina, Brasil, Paraguai e Uruguai. (BARTHELMESS, 2016)

De acordo com Paulo Renato Souza, ministro da Educação e do Desporto em 1995, um mercado com moeda e regras próprias no Cone Sul somente evoluiria a partir do conhecimento e respeito pelas distintas culturas das nações envolvidas(SOUZA, 1995).

Com a finalidade de alcançar essa evolução, a educação passou a ser vista como ponto-chave, estando ela presente desde as primeiras negociações que visavam a formação do bloco. Como consequência, o setor educacional do Mercosul foi "organizado praticamente de forma sincrônica à assinatura do Tratado de Assunção" (SOUZA, 1995, p. 3).

\footnotetext{
"A educação apresenta-se, nessas circunstâncias, como o cimento que dará consistência e solidez ao Mercosul. A intensificação e a extensão da cooperação nesse setor surgem, assim, como fundamentais para o sucesso de um processo de integração que leve à formação não só de uma nova identidade econômica, mas também de uma nova identidade cultural, dotada de visão regional, que concilie as diferenças e que estimule as concordâncias" (SOUZA, 1995, p. 5)
}

\footnotetext{
${ }^{4}$ Região conformada por Argentina, Brasil, Paraguai e Uruguai.
} 
Ou seja, apesar do objetivo da integração ser,em sua grande maioria,econômico, foi percebido que o seu alcance dependia de outros fatores, tais como a educação, e com ela o conhecimento cultural, capaz de possibilitar, de fato, uma integração entre os povos.

Entre outros resultados, a integração fez com que ensino de português fosse disseminado nos países de língua espanhola, e que o espanhol fosse ensinado no Brasil (SOUZA, 1995). A lei $\mathrm{n}^{\circ} 9.394 / 96^{5}$, mais conhecida como Lei de Diretrizes e Bases da Educação, é um exemplo disso. Ela determinou que o ensino de inglês fosse obrigatório nos currículos do ensino médio, e deu espaço para que o ensino de uma segunda língua, preferencialmente a espanhola, seja ofertada obrigatoriamente como optativa.

Ao fazer um percurso histórico do ensino de línguas estrangeiras no Brasil, Day (2012) aponta que esse ensino passou de sua total retirada em 1971 para a retomada em 1996 com o ensino obrigatório de inglês e a oferta optativa de língua espanhola.

A partir disso, Oliveira e Velasco (2018) concluem que esse acontecimento serviu, “entre outros motivos, para possibilitar uma maior comunicação do Brasil com outros países sul-americanos", resultado de uma política externa que buscava expandir-se tanto em níveis regionais quanto globais.

A opção pela oferta optativa de espanhol vai de encontro também com o parágrafo único do artigo $4^{\circ}$ da Constituição de 1988, no qual é afirmado que o Brasil deve buscar a "integração econômica, política, social e cultural dos povos da América Latina, visando à formação de uma comunidade latino-americana de nações" (BRASIL, 1988).

Em 2005 foi sancionada a lei 11.161, mais conhecida como "Lei do Espanhol". Ela determinou a obrigatoriedade do ensino com matrícula optativa de língua espanhola nas escolas públicas e privadas do Brasil. No entanto, ela foi revogada pela lei 13.415 , de fevereiro de 2017, adquirindo caráter facultativo e preferencial diante da obrigatoriedade do inglês. Com essa decisão, deixa-se espaço para que os gestores escolares não a entendam como importante, já que a oferta, além de ser optativa, depende da disponibilidade definida pelos sistemas de ensino.

A revogação do ensino de oferta obrigatória de espanhol repercutiu apresentandoimportantesdados, por exemplo, no quantitativo de professores de espanhol como língua estrangeira (E/LE) na rede estadual de ensino do Rio Grande do Norte.

\footnotetext{
${ }^{5}$ Lei $n^{\circ} 9.394 / 96$, artigo 35-A (BRASIL, 1996).
} 
Segundo dados da Secretaria Estadual de Educação (SEEC/RN), entre 2013 até 2017, o número de professores de E/LE no Estado vinha crescendo consideravelmente, apesar da leve queda entre 2015 e 2016. Contudo, entre 2017 e 2018, o total de professores caiu 12,57\%, e de 2018 para 2019, houve outra redução, desta vez de 3,32\% ${ }^{6}$.

A partir dessas informações, podemos associar que a diminuição de professores de E/LE na rede estadual está, de uma forma ou de outra, relacionada à lei responsável por revogar a 11.161/05, tendo em vista que a redução começou a ser observada somente após a sua sanção em 2017.

\section{Turismo no Rio Grande do Norte}

O Rio Grande do Norte, estado com 167 municípios e localizado no nordeste brasileiro, é um local repleto de belezas naturais e atrativos culturais responsáveis por conquistar muitos visitantes anualmente. Não apenas os mais de $400 \mathrm{~km}$ de litoral chamam a atenção dos turistas, mas também as tradicionais festas que ocorrem ao longo do ano, como o carnaval e carnatal, período junino e as festas religiosas do Estado.

Nos últimos anos, o turismo gastronômico e literário tem crescido em terras potiguares graças a festivais que atraem pessoas com os mais variados interesses. Além disso, regiões serranas, como Martins, Monte das Gameleiras e Serra de São Bento são lugares que chamam bastante atenção no inverno devido as baixas temperaturas, podendo alcançar até $15^{\circ}$.

Diante disso, não fica difícil imaginar a importância que este setor possui para o estado. No setor econômico, os destaques principais são serviço (70,9\%), indústria (24\%) e a agropecuária $(5,1 \%)^{7}$.

O turismo no RN é uma das mais importantes atividades para o desenvolvimento econômico regional e um mercado amplo laboral. Ele é responsável por empregar em torno de 120 mil pessoas, impactando, de forma direta ou indireta, 56 atividades econômicas. O Rio Grande do Norte recebe mais de dois milhões de visitantes por ano, tendo como principal destino o litoral do estado (ITEC, 2016).

\footnotetext{
${ }^{6}$ Fonte: 〈https://sigeduc.rn.gov.br/sigeduc/public/home.jsf>. Acesso em agosto de 2019.

${ }^{7}$ Fonte: Plano de Desenvolvimento Integrado do Turismo Sustentável - PDITS Polo Serrano, 2016.
} 
Imagem 1 - Polos Turísticos - Rio Grande do Norte.

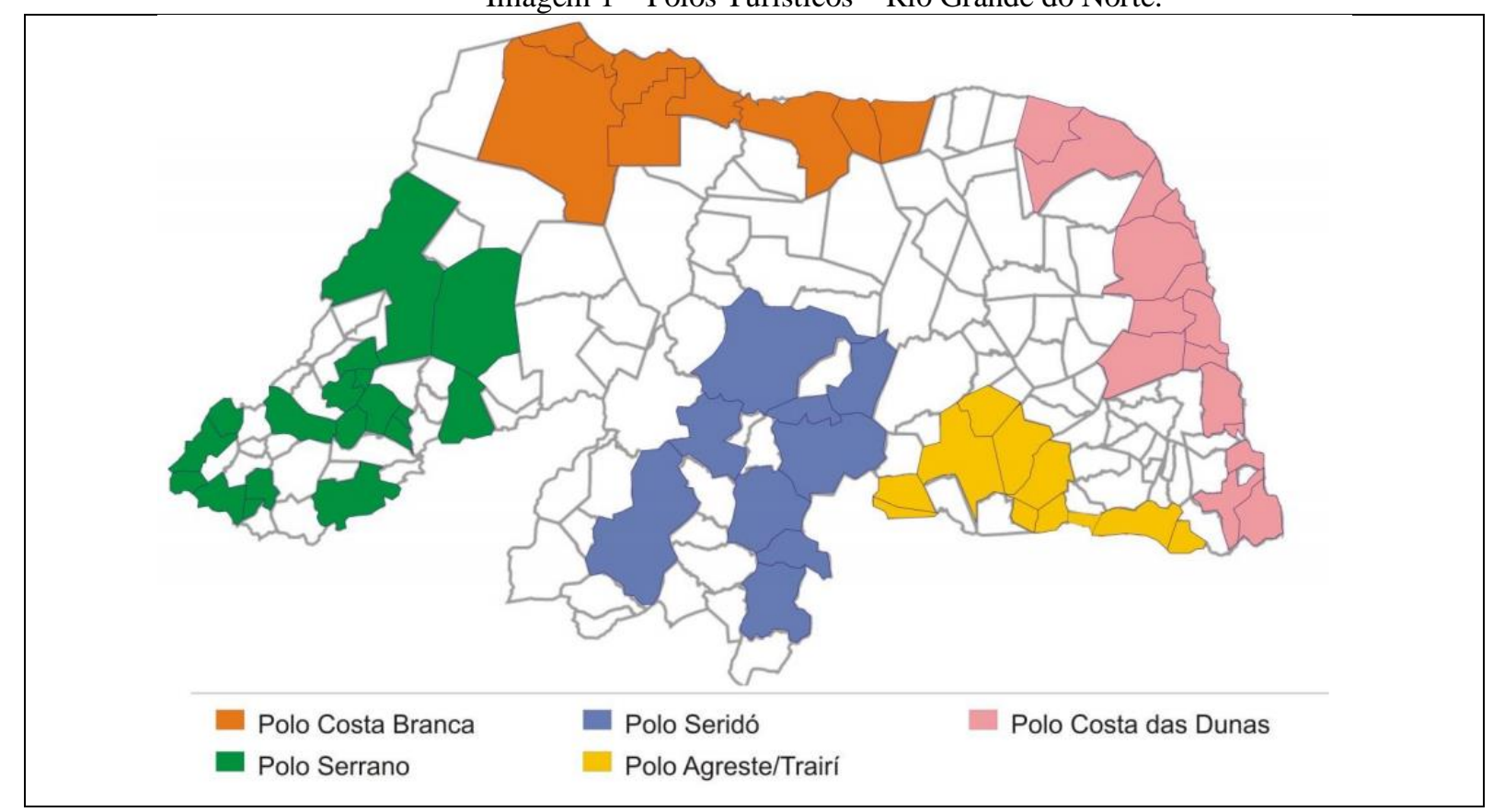

Fonte: ITCE, 2016. Disponível em: 〈http://www.rnsustentavel.rn.gov.br/>.

A imagem 1 mostra a divisão dos 5 polos turísticos do Rio Grande do Norte: AgresteTrairí, Costa Branca, Costa das Dunas, Seridó e Serrano. Essas regiões abrangem 65 municípios, todos "com potencialidades turísticas semelhantes como forma de promover e facilitar a estruturação e o planejamento do turismo sustentável, respeitando as tradições e as práticas sociais e culturais" (ITCE, 2016).

\section{Metodologia}

Para a elaboração deste trabalho, utilizamos como base pesquisas relacionadas ao âmbito do turismo, tanto em nível local quanto nacional, mais especificamente no que diz respeito ao Rio Grande do Norte. Nos respaldamos em alguns autores, como Day (2012) eBarthelmess (2016), e também em Leis federais sancionadas - ou revogadas - nos últimos anos.

Com o intuito de fundamentar nossas opiniões, analisamos informações presentes no Anuário Estatístico de Turismo 2019 - Ano Base 2018, documento disponibilizado na página 
online do Ministério do Turismo ${ }^{8}$;no Plano de Desenvolvimento Integrado do Turismo Sustentável, documento que pode ser encontrado na página online do Projeto RN Sustentável ${ }^{9}$, e em estudos realizados pela Federação de Comércio do Rio Grade do Norte (Fecomercio/RN).

As pesquisas bibliografias e documentais são todas de fontes abertas e relacionadas, direta ou indiretamente, ao tema proposto. Foram recolhidos dados de materiais publicados em páginas online de instituições públicas e privadas, além de órgãos públicos, tanto federais quanto estaduais.

Como muitas das informações encontradas estavam em forma de gráficos e tabelas, foi necessário realizar uma análise quantitativa referente tanto à presença de turistas estrangeiros no Rio Grande do Norte, assim como das demais variáveis analisadas ao longo do trabalho.

\section{Resultados e discussão}

\section{A língua espanhola no turismo potiguar}

As belezas do RN agradam não somente aos potiguares, mas também a pessoas de outras regiões do Brasil e até mesmo de outros países. Turistas dos mais variados lugares visitam o estado todos os anos, principalmente no período da alta estação, época que compreende os meses de dezembro, janeiro, fevereiro e julho.

Segundo dados do Anuário Estatístico de Turismo de 2019, 28.672 estrangeiros chegaram ao $\mathrm{RN}$ em 2018 por via aérea e marítima entre os meses de janeiro e dezembro. Desses, 10.389 - 36,2\% - eram de países que possuem o espanhol como língua nativa. ${ }^{10}$

Tabela 2 - Chegada de turistas ao RN por via aérea, terrestre e marítima - 2018.

\begin{tabular}{|c|c|c|}
\hline Argentinos & 8.900 & $31,00 \%$ \\
\hline Portugueses & 4.246 & $14,80 \%$ \\
\hline Italianos & 3.991 & $13,91 \%$ \\
\hline Franceses & 2.205 & $7,69 \%$ \\
\hline Noruegueses & 1.486 & $5,18 \%$ \\
\hline Alemães & 1.465 & $4,46 \%$ \\
\hline
\end{tabular}

\footnotetext{
${ }^{8}$ Disponível em: 〈http://www.dadosefatos.turismo.gov.br/2016-02-04-11-53-05.html>. Acesso em agosto de 2019.

${ }^{9}$ Disponível em: <http://www.rnsustentavel.rn.gov.br>. Acesso em agosto de 2019.

${ }^{10} 80,8 \%$ dos turistas que visitaram o RN em 2018 durante a alta estação chegaram ao estado por meio de transporte aéreo. Fonte: Fecomércio RN, 2019.
} 


\begin{tabular}{|c|c|c|}
\hline Espanhóis & 1.281 & $4,46 \%$ \\
\hline
\end{tabular}

Elaboração própria. Fonte: Anuário Estatístico de Turismo (2019).

A tabela 2 mostra as 7 nacionalidades com o maior número de turistas desembarcando no Rio Grande do Norte no ano de 2018. A partir desses dados, observamos a grande presença da língua espanhola nos estrangeiros visitantes, com destaque para argentinos e espanhóis, nacionalidades que ocupam, respectivamente, a $1^{\circ}$ e a $7^{\circ}$ posição no quantitativo total desses visitantes.

Já com a tabela 3 podemos observar a variedade cultural das pessoas hispanas que desembarcaram no RN, sendo sul-americana a maioria das nacionalidades, apesar da superior quantidade de visitantes argentinos em relação aos de outra nacionalidade.

Tabela 3 - Desembarques hispanos no RN em 2018.

\begin{tabular}{|c|c|}
\hline Argentinos & 8.900 \\
\hline Bolivianos & 7 \\
\hline Chilenos & 97 \\
\hline Colombianos & 1 \\
\hline Cubanos & 1.281 \\
\hline Espanhóis & 1 \\
\hline Hondurenhos & 6 \\
\hline Mexicanos & 1 \\
\hline Panamá & 19 \\
\hline Paraguaios & 8 \\
\hline Peruanos & 45 \\
\hline Uruguaios & 14 \\
\hline Venezuelanos & $\mathbf{1 0 . 3 8 9}$ \\
\hline Total &
\end{tabular}

Elaboração própria. Fonte: Anuário Estatístico de Turismo (2019).

Para atender a essa demanda, é necessária uma preparação tanto na parte da infraestrutura quanto na qualificação profissional das pessoas que trabalham para recepcionalos, em especial no que se refere à comunicação.

É importante que os profissionais do setor turístico do RN estejam capacitados para comunicar-se com o turista estrangeiro que visita o estado, em especial o de origem hispânica, 
já que eles representam quase a metade dos visitantes de fora. Fazer com que esse turista, assim como os demais, seja bem atendido e consiga comunicar-se durante a sua estadia faz com que o estado e a sociedade potiguar no geral sejam vistos de forma positiva, o que pode acabar influenciando o retorno futuro do turista ou até mesmo impulsionando a vinda de outros.

Em um estudo ${ }^{11}$ realizado pelo Instituto de Pesquisa e Desenvolvimento do Comércio (IPDC), que é ligado à Federação do Comércio de Bens, Serviços, e Turismo do RN (Fecomércio RN), foi analisado o perfil dos turistas que visitaram o Rio Grande do Norte na alta estação de 2019 - dezembro, janeiro, fevereiro e julho -, e os resultados foram comparados com o estudo realizado no mesmo período dos anos anteriores.

Dentre os dados obtidos, observou-se que, no período de alta estação, o turismo estrangeiro em 2019 representou 21,5\% do total no RN, mostrando uma leve queda em relação à crescente presença internacional dos últimos anos (Gráfico 1).

Ao observar os países de origem dos turistas estrangeiros que visitaram o estado, temse que, em 2018, 96\% deles vinham de países que possuem o espanhol como língua oficial, representando praticamente a totalidade do turismo estrangeiro no RN. Em 2019, mesmo com a queda no total de visitantes estrangeiros em relação ao ano anterior, os falantes de espanhol representaram $85,5 \%$, quantidade ainda superior em relação as pessoas oriundas de países que possuem como idioma oficial outras línguas (Tabela 4).

Gráfico 1: Perfil turístico do Rio Grande do Norte na alta estação.

\footnotetext{
${ }^{11}$ Perfil do Turista na Alta Estação 2019. Disponível em <http://fecomerciorn.com.br/pesquisas/perfil-doturista-na-alta-estacao-2019/>. Acesso em agosto de 2019.
} 


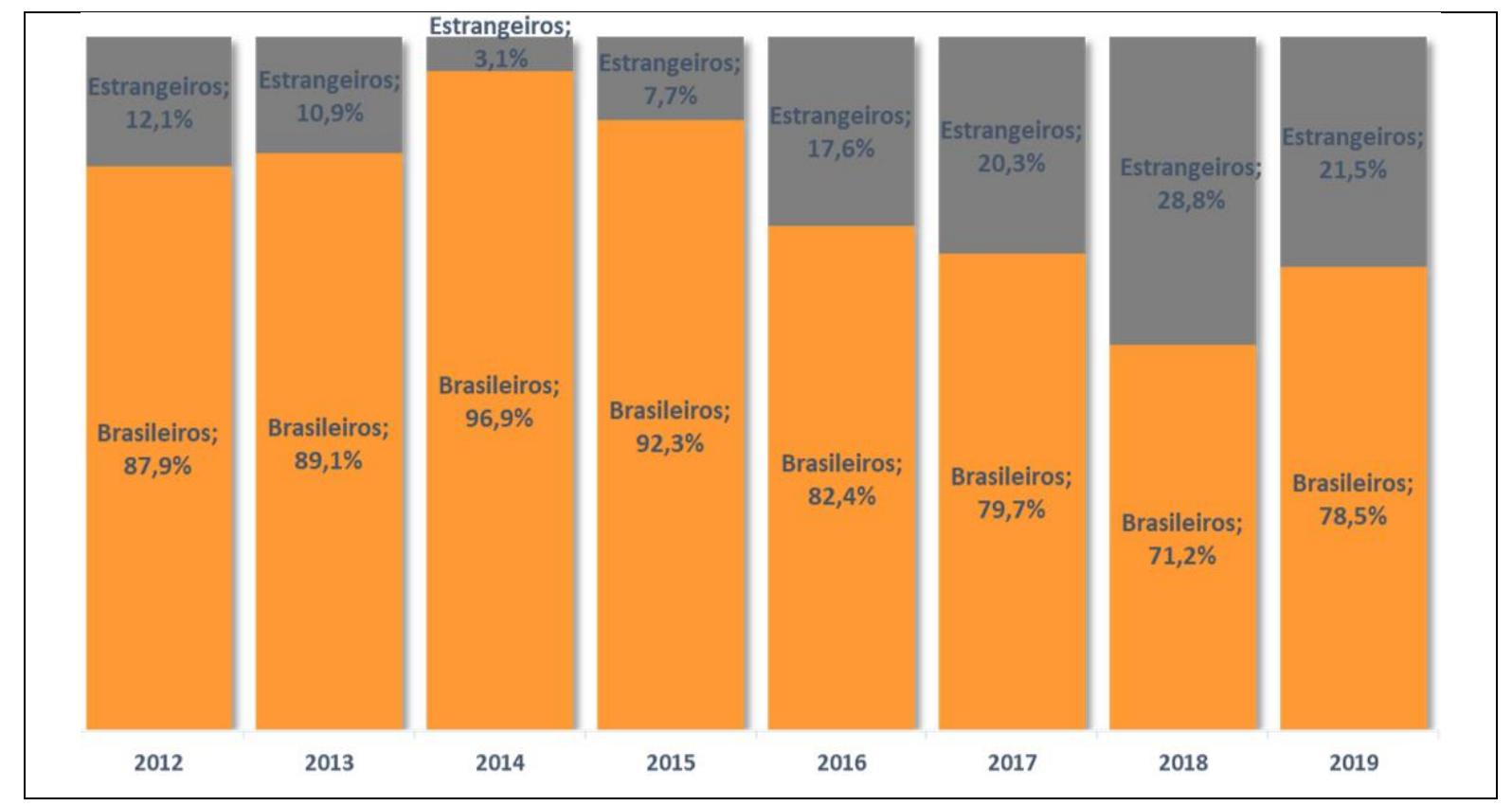

Fonte: Fecomério RN (2019).

Os turistas que visitaram o RN em 2019 e vêm em sua grande maioria da Argentina $(14,4 \%)$, seguidos por Uruguai $(2,1 \%)$, Chile $(0,9 \%)$, Paraguai $(0,7 \%)$ e Espanha $(0,3 \%)$. No mesmo período de 2018, os argentinos já representavam o maior percentual dos visitantes nativos do espanhol (25\%), seguidos por Paraguai, Uruguai, Chile e Espanha (Tabela 4).

Tabela 4 - País de origem dos turistas na alta estação.

\begin{tabular}{|c|c|c|c|c|c|c|c|c|}
\hline País de origem & 2012 & 2013 & 2014 & 2015 & 2016 & 2017 & 2018 & 2019 \\
\hline Brasil & $87,9 \%$ & $89,1 \%$ & $96,9 \%$ & $92,3 \%$ & $82,4 \%$ & $79,7 \%$ & $71,2 \%$ & $78,5 \%$ \\
\hline Argentina & $3,7 \%$ & $5,2 \%$ & $0,5 \%$ & $1,5 \%$ & $6,7 \%$ & $7,7 \%$ & $25,9 \%$ & $14,4 \%$ \\
\hline Itália & $3,4 \%$ & $1,0 \%$ & 0,3\% & $2,0 \%$ & $1,7 \%$ & $1,7 \%$ & $0,5 \%$ & $0,2 \%$ \\
\hline Portugal & $2,0 \%$ & $2,5 \%$ & $0,3 \%$ & $1,5 \%$ & $0,9 \%$ & $2,0 \%$ & $0,2 \%$ & $0,9 \%$ \\
\hline Espanha & $0,6 \%$ & $0,5 \%$ & $0,5 \%$ & $1,0 \%$ & $0,0 \%$ & $1,7 \%$ & $0,0 \%$ & $0,3 \%$ \\
\hline Chile & $0,3 \%$ & $0,0 \%$ & $0,8 \%$ & $0,0 \%$ & $1,5 \%$ & $0,2 \%$ & $0,5 \%$ & $0,9 \%$ \\
\hline Noruega & $0,3 \%$ & $0,0 \%$ & $0,0 \%$ & $0,0 \%$ & $0,2 \%$ & $0,0 \%$ & $0,2 \%$ & $0,3 \%$ \\
\hline Uruguai & $0,3 \%$ & $0,5 \%$ & $0,0 \%$ & $0,0 \%$ & $0,9 \%$ & $1,4 \%$ & $0,6 \%$ & $2,1 \%$ \\
\hline Paraguai & $0,0 \%$ & $0,0 \%$ & $0,5 \%$ & $0,5 \%$ & $1,5 \%$ & $0,9 \%$ & $0,7 \%$ & $0,7 \%$ \\
\hline Outros & $1,5 \%$ & $1,2 \%$ & $0,2 \%$ & $1,2 \%$ & $4,2 \%$ & $4,7 \%$ & $0,1 \%$ & $1,7 \%$ \\
\hline
\end{tabular}

Fonte: Fecomércio RN (2019).

Ainda segundo os dados da Fecomércio RN (2019), o gasto diário individual do turista passou de R \$ 208,41 em 2016 para R \$ 322,78 em 2019, representando um aumento de 54,8\% em três anos (Tabela 5), que implica em uma melhora na economia do Estado. 


\begin{tabular}{|c|c|c|c|c|c|}
\hline Seguimento & 2015 & 2016 & 2017 & 2018 & 2019 \\
\hline Hospedagem $\mathbf{R} \$$ & $R \$ 94,43$ & $R \$ 90,98$ & $R \$ 93,29$ & $\mathrm{R} \$ 121,27$ & $R \$ 138,63$ \\
\hline Alimentação R\$ & $\mathrm{R} \$ \mathbf{4 2 , 8 2}$ & $\mathrm{R} \$ \mathbf{5 2 , 1 6}$ & $\mathrm{R} \$ \mathbf{4 6 , 0 0}$ & $\mathrm{R} \$ \mathbf{5 5 , 1 5}$ & $R \$ 63,64$ \\
\hline Transporte local $\mathbf{R} \$$ & $R \$ 16,84$ & $R \$ 15,76$ & $R \$ 19,42$ & $\mathrm{R} \$ 28,11$ & $R \$ 30,04$ \\
\hline Diversão R\$ & $\mathrm{R} \$ 31,65$ & $\mathrm{R} \$ 25,07$ & $\mathrm{R} \$ \mathbf{4 3 , 5 2}$ & $R \$ 66,53$ & $\mathbf{R} \$ \mathbf{5 2 , 5 0}$ \\
\hline Compras $\mathbf{R} \$$ & $R \$ 25,18$ & $\mathrm{R} \$ 24,44$ & $\mathbf{R} \$ \mathbf{3 2 , 9 3}$ & $\mathrm{R} \$ \mathbf{4 7 , 2 0}$ & $R \$ 37,97$ \\
\hline $\begin{array}{l}\text { Gasto médio per } \\
\text { capita/dia }\end{array}$ & $R \$ 210,92$ & $R \$ 208,41$ & $R \$ 235,16$ & $\mathrm{R} \$ 318,25$ & $R \$ 322,78$ \\
\hline
\end{tabular}

Fonte: Fecomércio RN (2019).

Apesar da redução de 7,3\% em relação a 2018 no quantitativo geral, o turista estrangeiro continua a ser responsável por um gasto individual médio maior do que o turista nacional, superando em $12 \%$ o valor gasto pelos brasileiros (Tabela 6). A partir disso destacamos que, mesmo que o número de turistas estrangeiros seja inferior ao de turistas nacionais, o valor gasto por eles com bens e serviços durante a sua estadia no RN continua a representar uma considerável receita para o turismo potiguar.

Tabela 6 - Gasto médio individual diário do turista por segmento e nacionalidade - R\$.

\begin{tabular}{|ccc|}
\hline Nacionalidade & Brasileiros & Estrangeiros \\
\hline Hospedagem $\mathbf{R} \$$ & $\mathbf{R} \mathbf{1 3 3 , 2 5}$ & $\mathbf{R} \mathbf{1 5 4 , 6 8}$ \\
\hline Alimentação $\mathbf{R} \$$ & $\mathbf{R} \mathbf{6 1 , 4 9}$ & $\mathbf{R} \mathbf{7 1 , 0 9}$ \\
\hline Transporte local $\mathbf{R} \$$ & $\mathbf{R} \mathbf{2 9 , 1 9}$ & $\mathbf{R} \mathbf{3 3 , 2 2}$ \\
\hline Diversão $\mathbf{R} \$$ & $\mathbf{R} \mathbf{5 1 , 4 6}$ & $\mathbf{R} \mathbf{5 6 , 5 0}$ \\
\hline Compras $\mathbf{R} \$$ & $\mathbf{R} \mathbf{3 8 , 3 8}$ & $\mathbf{R} \mathbf{3 6 , 1 5}$ \\
\hline Total & $\mathbf{R} \mathbf{3 1 3 , 7 7}$ & $\mathbf{R} \mathbf{3 5 1 , 6 5}$ \\
\hline
\end{tabular}

Fonte: Fecomércio RN (2019).

Ainda segundo a pesquisa da Fecomércio RN (2019), 56,1\% dos turistas que vêm ao Rio Grande do Norte - brasileiros e estrangeiros - hospedam-se em hotéis, enquanto que $19,8 \%$ optam por pousadas ${ }^{12}$, fato que ressalta a importância dos trabalhadores desses ambientes - recepcionistas, camareiros, mensageiros, etc. - possuírem pelo menos conhecimento básico para se comunicar com os hóspedes falantes de espanhol.

\footnotetext{
12 Tipo de hospedagem: Hotel - 56,1\%; Pousada - 19,8\%; Casa de parentes/amigos -14,3\%; Casa alugada/Apartamento - 4,4\%; Flat - 3,6\%; Albergue/Alojamento - 1,7\%; Outros - 1,6\%; NR - 0,9\%. Fonte: Fecomércio RN, 2019.
} 
A mesma pesquisa indica que $44,3 \%{ }^{13}$ das pessoas que vieram ao estado na alta estação foram influenciados pelos comentários de parentes ou amigos, mostrando que a boa estadia do turista durante determinado período pode gerar boa impressões e atrair mais visitantes com o passar dos anos.

No contexto do projeto de extensão chamado "CONOCE, COMPRENDE y DIME EN ESPAÑOL" ${ }^{14}$, fruto da parceria entre o NUPELE ${ }^{15} /$ IFRN $^{16}$ Campus Natal-Central com a Secretaria de Turismo do Rio Grande do Norte (SETUR/RN), foi realizada a $1^{\circ}$ oferta dos cursos do projeto, entre os dias 18 de julho e 24 de setembro, ambas para trabalhadores de hotéis, especialmente os que exercem a função de recepcionistas, camareiros e/ou mensageiros.O projeto obteve um totalde 638 inscrições para o preenchimento de 45 vagas, sendo 30 para o nível iniciante e 15 para o nível intermediário.

A ampla procura indicou o grande interesse da comunidade em adquirir conhecimentos de língua espanhola, mais especificamente voltados para o trabalho que desempenham no âmbito do turismo. Ressaltamos que a inscrição estava delimitada para pessoas que atuassem em hotéis do RN no âmbito do Turismo.

Ao preencher o formulário de inscrição ${ }^{17}$ para os cursos do referido projeto de extensão do IFRN, os candidatos deveriam responder algumas perguntas, todas com o objetivo de identificar o público interessado nos cursos. As respostas obtidas foram analisadas a partir da observação dos gráficos $2,3,4$ e 5.

Como pode ser apreciadono Gráfico 2, 401 dos inscritos (63,2\%) não haviam antes estudado espanhol. Essa primeira informação nos revela que a maior parte da procura pelas vagas no curso foi feita por pessoas interessadas que ainda não tinham estudado espanhol.

Gráfico 2: Você já estudou língua espanhola? Quantos semestres? ${ }^{18}$

\footnotetext{
${ }^{13}$ Influência da viagem a passeio: Comentário de parentes/amigos - 44,3\%; Já conhecia o local - 27,3\%; Agência de viagem - 8,1\%; Internet - 9,9\%; Propaganda - 2,4\%; Outras - 13,9\%; NS/NR - 0,5\%. Fonte: Fecomério RN, 2019.

${ }^{14}$ Disponível em: 〈https://suap.ifrn.edu.br/projetos/projeto/4481/>. Acesso em setembro de 2019.

${ }^{15}$ Núcleo de Estudos e Pesquisa de espanhol como Língua Estrangeira no Brasil.

${ }^{16}$ Instituto Federal de Educação, Ciência e Tecnologia do Rio Grande do Norte.

${ }^{17}$ Disponível em: 〈http://tiny.cc/1zj6cz>. Acesso em setembro de 2019.

${ }^{18}$ Não - 63,2\%; Sim, 1 semestre - 19,7\%; Sim, 2 semestres - 9,2\%; Sim, 3 semestres - 3,8\%; Sim, mais de 4 semestres $-3,9 \%$; Sim, 4 semestres $-0,2 \%$.
} 


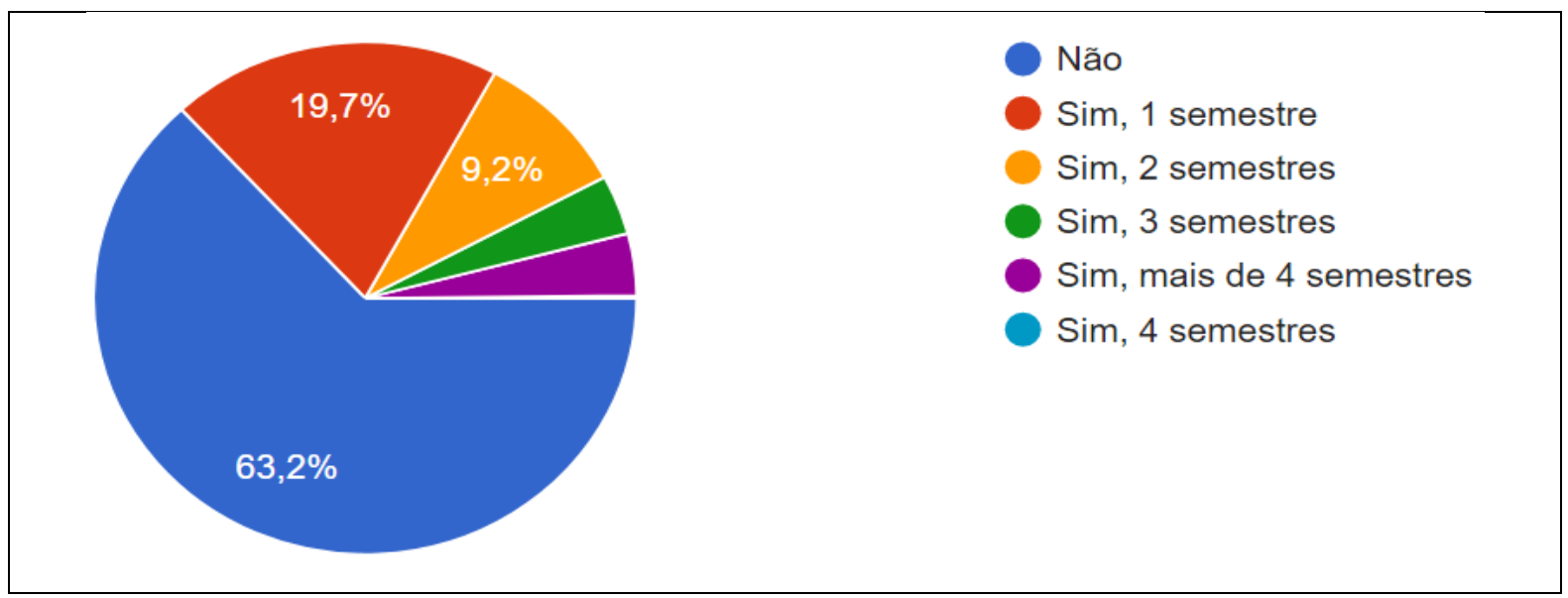

Fonte: NUPELE/IFRN, 2019.

No Gráfico 3 é indagado se as pessoas que estudaram espanhol se consideravam ou não fluentes. Como resultado, obtivemos que 602 (94,4\%) pessoas não se consideravam fluentes em língua espanhola, constatação que demonstra que a grande maioria dos inscritos reconhecianão possuir conhecimentos suficientes de espanhol para considerar-se fluente na língua.

Gráfico 3: Se sua resposta anterior foi SIM, você considera-se fluente em espanhol ${ }^{19}$

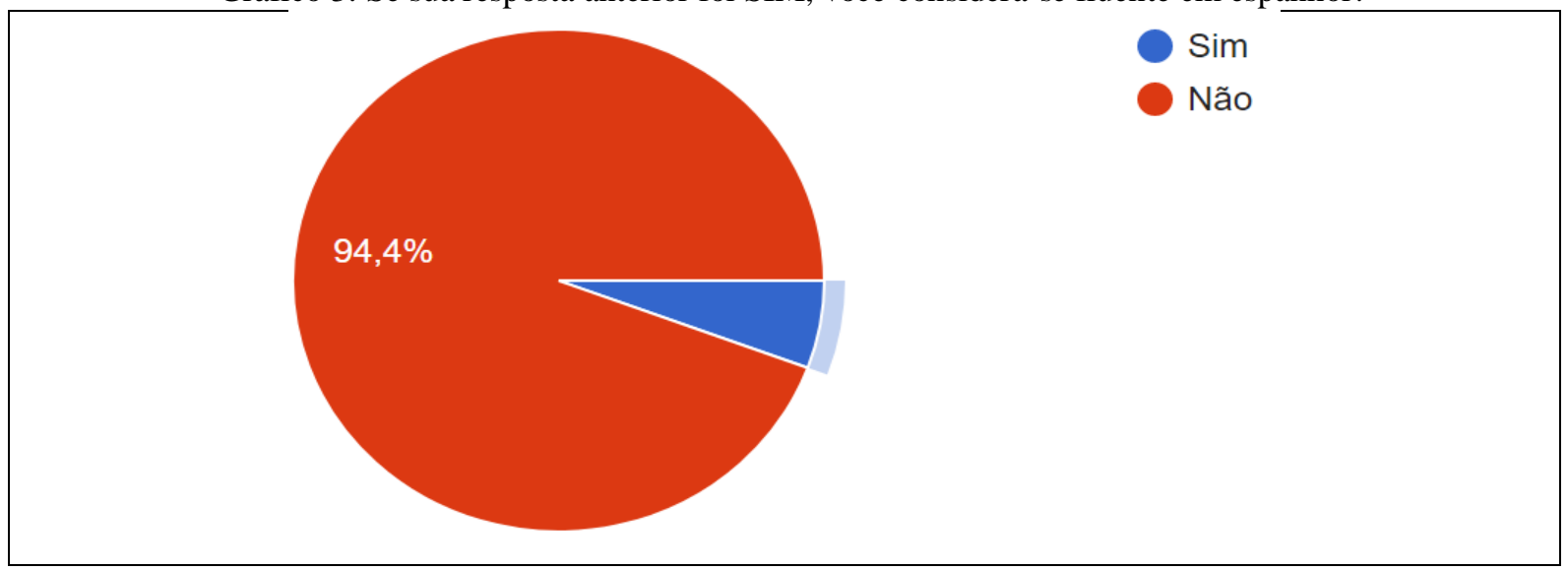

Fonte: NUPELE/IFRN, 2019.

Já no gráfico 4, praticamente a metade dos inscritos - 318 pessoas $(49,7 \%)$ - utilizam o espanhol no trabalho, e a outra metade ficou dividida entre os que não utilizam - 160 pessoas $(25,1 \%)$ - ou pouco utilizam - 161 pessoas $(25,2 \%)$ - o espanhol.

${ }^{19} \operatorname{Sim}-5,6 \%$; Não - 94.4\%. 
Gráfico 4: Você usa a língua espanhola no seu trabalho? ${ }^{20}$

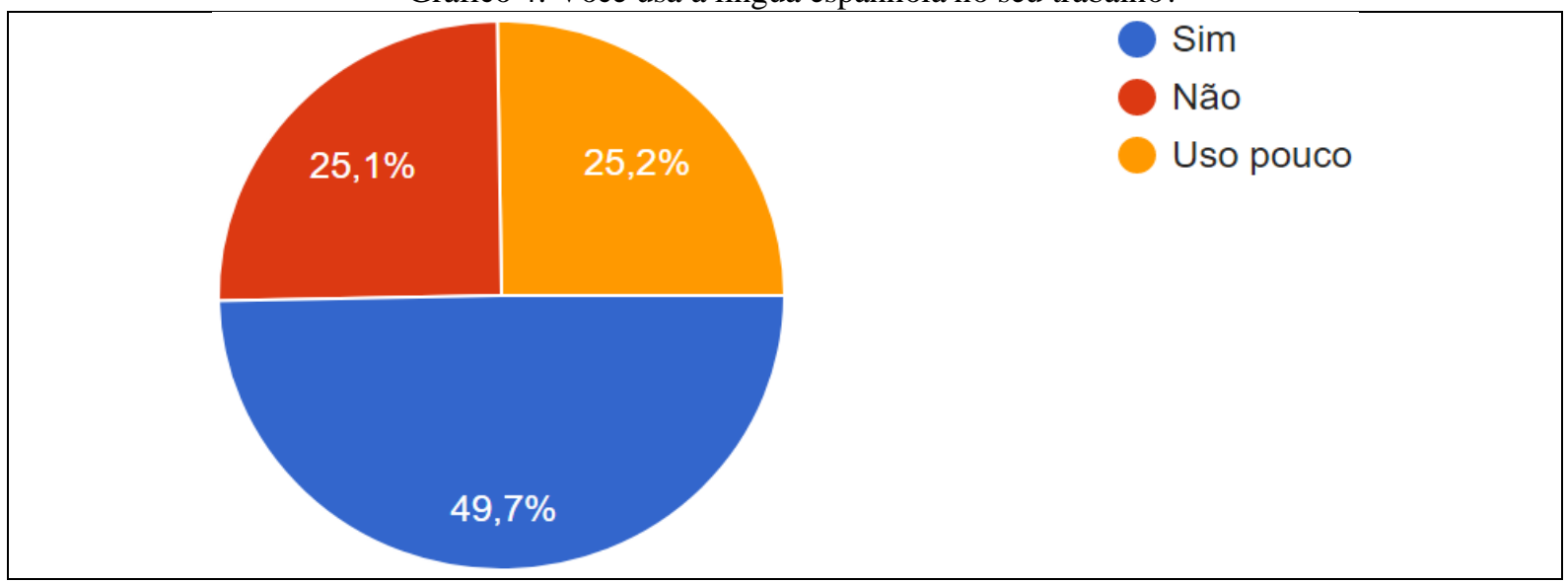

Fonte: NUPELE/IFRN, 2019.

Um dos dados que consideramos mais interessante se revela no Gráfico 5. Obtivemos que, apesar de os cursos ofertados serem voltados para pessoas que trabalham com o turismo no Rio Grande do Norte, mais especificamente os recepcionistas, camareiros e mensageiros de hotel, 237 candidatos - 37\% do total de inscritos - afirmaram não estar trabalhando na área do turismo, ou que ainda não trabalham, demostrando grande interesse por aprender a comunicar-se no idioma espanhol e consequentemente também em trabalhar na área turística.

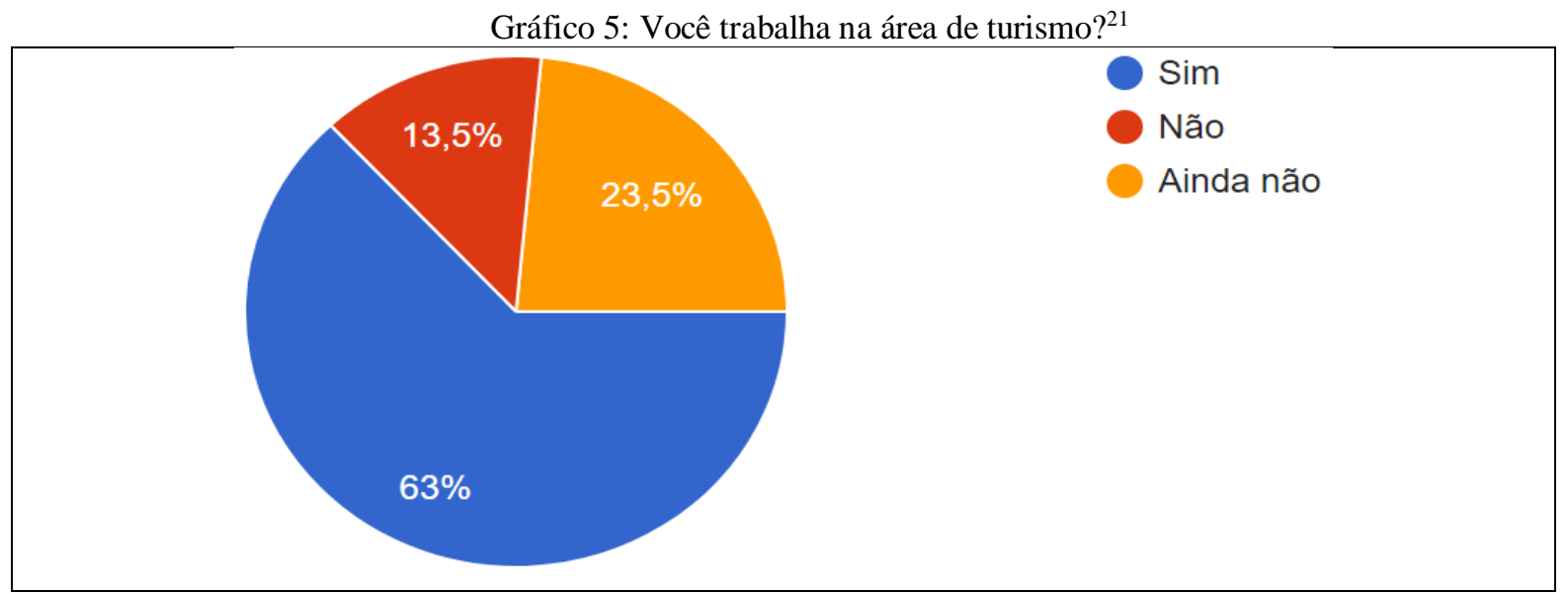

Fonte: NUPELE/IFRN, 2019.

Ressaltamos que, se o ensino de língua espanhola se mantivesse como importante para o cidadão como uma qualificação que pode abrir-lhe as portas do mercado de trabalho neste

\footnotetext{
${ }^{20} \mathrm{Sim}-49,7 \%$; Não - 25,1\%; Uso pouco - 25,2\%.
}

${ }^{21} \mathrm{Sim}-63 \%$; Não - 13,5\%; Ainda não - 23,5\%. 
segmento, certamente haveria possibilidades de uma sociedade melhor equilibrada alavancando a economia do RN numa das suas potencialidades como é, a nosso ver, o Turismo.

\section{Conclusões}

Pelo exposto, entendemos o turismo como um dossetores econômicos mais importantes do estado do RN, sendo um dos que mais gera renda, podendo ser o responsável por alavancar a economia local por meios de seus mais distintos setores, como alimentação, transporte, hospedagem, etc., levando-nos a considerar esse fato como uma razão mais do que suficiente para investir no ensino de espanhol na educação básica e na formaçao técnica de todos aqueles que optam por trabalhar nesse setor da economia do Estado.

Diante do levantamento realizado pela Fecomercio/RN, fica constatada a grande presença de turistas hispanos no Rio Grande no Norte, chegando a representar $96 \%$ dos turistas estrangeiros na alta estação de 2018 e 85,6\% em 2019, fato que nos leva a concluir que o turista estrangeiro que visita o $\mathrm{RN}$ é, em sua grande maioria, falante de espanhol.

Para que essa demanda turística potiguar seja atendida, em especial a parte internacional falante de espanhol, é necessário investimento na capacitação linguística dos trabalhadores que lidam diariamente com pessoas de outros países que visitam o estado, por mais variados que sejam os seus objetivos.

Diante disso, percebemos a necessidade de investimentos em políticas educacionais, mais especificamente as linguísticas, de forma que, ao concluírem o ensino básico, jovens potiguares possam ter a possibilidade de competir por uma oferta de trabalho âmbito turístico.

Acreditamos ser possível e benéfico para a sociedade potiguar pensar em políticas públicas de forma que uma possa completar os objetivos da outra, e não somente refleti-las de maneira isolada. Os objetivos econômicos almejados pelo o turismo no $\mathrm{RN}$, uma vez pensados em consonância com políticas linguísticas voltadas a atender a uma demanda específica, possibilitam uma maior capacitação da população local e geram retornos financeiros e sociais ainda maiores para a sociedade potiguar.

Pensar no ensino de espanhol como língua estrangeira no âmbito escolar é visionar futuras possibilidades que os estudantes potiguares podem vir a ter diante da realidade econômica do estado. Possibilitar ainda mais o ensino de espanhol nas escolas públicas 
significa capacitar os jovens estudantes para realidades que eles hão de enfrentar ao concluírem o ensino médio.

\section{Referências}

BARTHELMESS, E. As relações Brasil-Argentina no aniversário da Declaração do Iguaçu. In: Cadernos de Política Exterior, v. 3, p. 27-43, 2016.

BRASIL. Constituição (1988). Constituição da República Federativa do Brasil. Brasília, DF: Senado, 1998.

BRASIL, Lei n. 9.394, de 20 de dezembro de 1996. Estabelece as diretrizes e bases da educação nacional, Brasília, DF, dezembro 1996.

BRASIL, Lei n. 11.161, de 5 de agosto de 2005. Dispõe sobre o ensino de língua espanhola. Brasília, DF, agosto 2005.

BRASIL, Lei n. 13.415, de 16 de fevereiro de 2017. Altera as Leis $\mathbf{n}^{\mathbf{0}} \mathbf{s}$ 9.394, de 20 de dezembro de 1996, que estabelece as diretrizes e bases da educação (...); revoga a Lei $\mathbf{n}^{0}$ 11.161, de 5 de agosto de 2005 (...). Brasília-DF, fevereiro 2017.

BRASIL. Anuário Estatístico de Turismo - 2019. In: Ministério do Turismo. Brasília-DF, v. 6, maio 2019.

CERVANTES, Instituto. El español: una lengua viva. Informe 2018. In: Centro Virtual Cervantes. 1997-2019.

CERVANTES, Instituto. 577 millones de personas hablan español, el $\mathbf{7 , 6 \%}$ de la población mundial. In: Instituto Cervantes (España). Madrid, novembro, 2018.

DAY, Kelly. Ensino de línguas estrangeiras no Brasil: entre a escolha obrigatória e a obrigatoriedade voluntária. In Revista Escrita, Rio de Janeiro, nº 15, p. 1-13, 2012.

OLIVEIRA, Lucas; VELASCO, Maria. Educação e desenvolvimento - O MERCOSUL no sistema educacional brasileiro. In: VI Congresso Internacional das Licenciaturas - PDVL, 2018, João Pessoa - PB. Anaisdo VI Congresso Internacional das Licenciaturas - PDVL, 2018.

RIO GRANDE DO NORTE. O Rio Grande do Norte. In: Secretaria de Turismo, 2019. Disponível em: <http://setur.rn.gov.br/?page id=4050>. Acesso em agosto de 2019.

RIO GRANDE DO NORTE. Plano de Desenvolvimento Integrado do Turismo Sustentável - PDITS Polo Serrano. Natal, RN: SETUR/RN, v.1, setembro/2016.

RIO GRANDE DO NORTE. Turismo. In: Portal do Governo do RN, 2019. Disponível em: <http://www.rn.gov.br/>. Acesso em agosto de 2019. 
SIMÕES, Antônio. Integração: sonho e realidade na América do Sul. Brasília: FUNAG, 2010.

SOUZA, Paulo Renato. A educação no MERCOSUL. Em Aberto, Brasília, ano 15, n.68, out. /dez. 1995. 